\title{
Reexamining the MJO Moisture Mode Theories with Normalized Phase Evolutions
}

\author{
LU WANG \\ Key Laboratory of Meteorological Disaster, Ministry of Education, and Joint International Research Laboratory of Climate \\ and Environmental Change, and Collaborative Innovation Center on Forecast and Evaluation of Meteorological Disasters, \\ Nanjing University of Information Science and Technology, Nanjing, and LASG, Institute of Atmospheric Physics, \\ Chinese Academy of Sciences, Beijing, China

\section{TIM LI} \\ International Pacific Research Center, University of Hawai'i at Mānoa, Honolulu, Hawaii, and Key Laboratory of \\ Meteorological Disaster, Ministry of Education, and Joint International Research Laboratory of Climate and \\ Environmental Change, and Collaborative Innovation Center on Forecast and Evaluation of Meteorological Disasters, \\ Nanjing University of Information Science and Technology, Nanjing, China
}

(Manuscript received 22 March 2020, in final form 10 July 2020)

\begin{abstract}
A normalization method is applied to MJO-scale precipitation and column integrated moist static energy (MSE) anomalies to clearly illustrate the phase evolution of MJO. It is found that the MJO peak phases do not move smoothly, rather they jump from the original convective region to a new location to its east. Such a discontinuous phase evolution is related to the emerging and developing of new congestus convection to the east of the preexisting deep convection. While the characteristic length scale of the phase jump depends on a Kelvin wave response, the associated time scale represents the establishment of an unstable stratification in the front due to boundary layer moistening. The combined effect of the aforementioned characteristic length and time scales determines the observed slow eastward phase speed. Such a phase evolution characteristic seems to support the moisture mode theory of the second type that emphasizes the boundary layer moisture asymmetry, because the moisture mode theory of the first type, which emphasizes the moisture or MSE tendency asymmetry, might favor more "smooth" phase propagation. A longitudinal-location-dependent premoistening mechanism is found based on moisture budget analysis. For the MJO in the eastern Indian Ocean, the premoistening in front of the MJO convection arises from vertical advection, whereas for the MJO over the western Pacific Ocean, it is attributed to the surface evaporating process.
\end{abstract}

KEYWORDS: Tropics; Madden-Julian oscillation; Intraseasonal variability

\section{Introduction}

The Madden-Julian oscillation (MJO) is the most prominent atmospheric intraseasonal variability in the tropics. The discovery of this phenomenon could be traced back to Madden and Julian (1972), or even earlier by Xie et al. (1963) (see recent review papers by Li et al. 2018, 2020). The MJO is featured by a slow eastwardmoving envelope of large-scale convective anomalies with a period of 30-60 days and zonal wavenumbers of 1-3 (e.g., Madden and Julian 1972; Li 2014). It has a horizontal pattern of the Rossby-Kelvin wave couplet (Wang and Li 1994; Hendon and Salby 1994) and a

\footnotetext{
Corresponding author: Tim Li, timli@hawaii.edu
}

westward tilting vertical structure (Sperber 2003; Hsu and Li 2012; Wang et al. 2017). Although its convection is confined in the tropics, the MJO exerts a remote impact on weather and climate phenomena across different temporal scales over the globe (e.g., Liebmann et al. 1994; Kessler and Kleeman 2000; Zhang 2005; Chen et al. 2016a,b). It is the major predictability source for subseasonal forecast (e.g., Xiang et al. 2015; Wang et al. 2019). Therefore, understanding the physical mechanisms of MJO initiation and propagation is critical for beyond weather-scale prediction.

Early MJO theories emphasized the role of equatorial wave and boundary layer dynamics while neglecting MJO-scale moisture changes (e.g., Wang 1988; Wang and Rui 1990; Wang and Li 1994; Li and Wang 1994). In 
recent years, the role of perturbation moisture was emphasized, as MJO-scale precipitation is in general in phase with the moisture perturbation and the model simulation of MJO is much improved when convection is set more sensitive to moisture (see a review in this topic by Kim and Maloney 2017). Therefore, the MJO, to the first order of approximation, may be regarded as a moisture mode.

The moisture mode theory of the MJO can be separated into two types. The first type emphasizes the role of zonal asymmetry of column integrated moisture or moist static energy (MSE) tendency in eastward propagation (e.g., Maloney 2009; Raymond and Fuchs 2009; Sobel and Maloney 2013; Li and $\mathrm{Hu}$ 2019). Using a column integrated moisture tendency equation, Sobel and Maloney (2013) derived an analytic solution with an eastward phase speed, but such a phase speed is too slow compared to the observations. This theoretical framework was later improved by adding anomalous meridional advection (Adames and Kim 2016) and anomalous vertical advection ( $\mathrm{Li}$ and $\mathrm{Hu}$ 2019). The MSE tendency asymmetry framework has been widely used in understanding the fundamental dynamics of the MJO, as well as projected changes of MJO in warming scenario. Through comparing the propagating and the nonpropagating MJO simulation groups from 27 state-of-the-art general circulation models (GCMs), Wang et al. (2017) revealed that the fundamental processes that distinguish the two model groups lie in the vertical advection of mean MSE by MJO-scale vertical motion and the advection of mean moisture by MJO meridional wind. It has been shown using the same MSE diagnostic framework that the eastward propagation of the MJO will be accelerated in a warmer climate (e.g., Maloney et al. 2019), due to increase of the mean meridional moisture gradient (e.g., Rushley et al. 2019; Cui and Li 2019).

A key premise in the first type of the moisture theory above is that the eastward propagation of MJO lies in the MSE tendency asymmetry, regardless of whether or not the MSE itself is symmetric (relative to the MJO convection). This is analogous to a simple one-dimensional advection equation:

$$
d u / d t+C d u / d x=0
$$

where $C$ is a positive constant. Given a sine wave solution for $u$, a positive (negative) tendency always appears to the east (west) of the peak phase of $u$. The theoretical solution of this advection equation is that the maximum phase of the sine wave moves at a constant phase speed of $C$. As illustrated by Fig. 1a, the column-integrated MSE anomaly, denoted by a single sine wave with its peaks at $0^{\circ}$, shows a maximum zonal tendency at $+90^{\circ}$
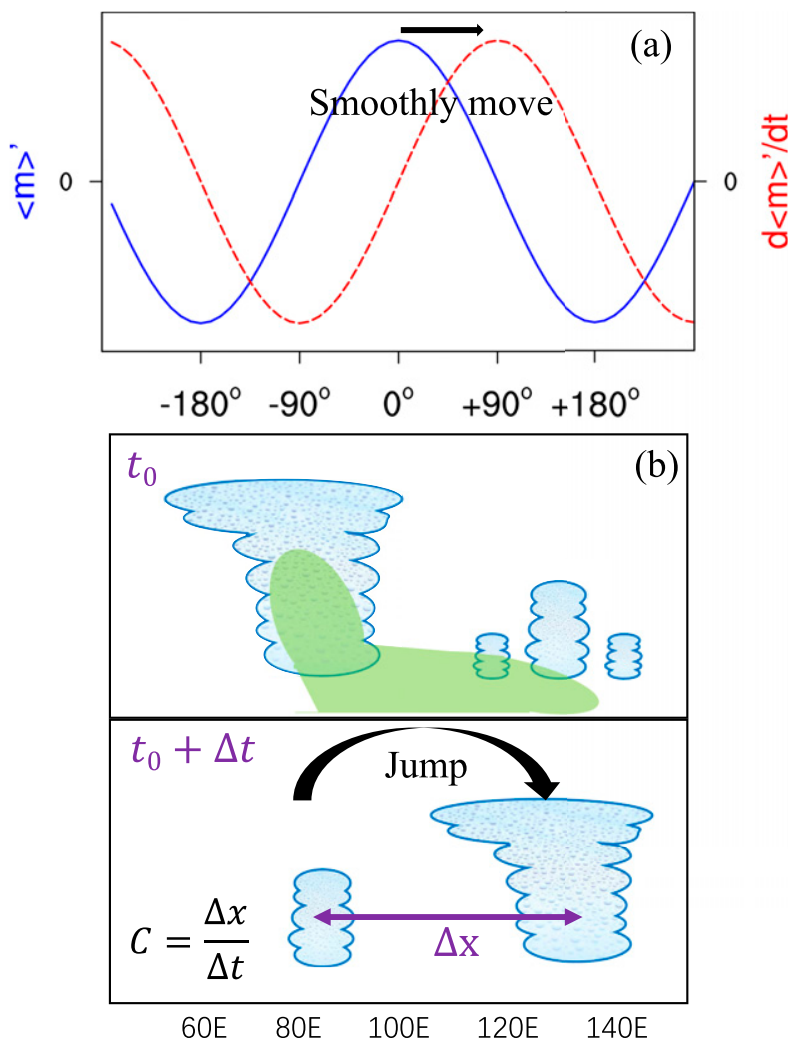

FIG. 1. Schematic diagrams illustrating the two differing moisture mode theories. (a) In the first type, the zonally asymmetric distribution of column-integrated MSE tendency (red curve) relative to the MJO convection, which is denoted by the maximum of column-integrated MSE (blue curve), is conductive to a smoothly eastward propagation. (b) In the second type, the asymmetric moisture (shaded in green) relative to the convective center is essential in setting up an unstable stratification and in triggering a new convection to the east of preexisting MJO convection; this framework indicates a discontinuous and jumping feature of the eastward propagation. The phase speed $C$ is determined by the time scale $\Delta t$ and the length scale $\Delta x$ for the new convection to the east.

and a minimum zonal tendency at $-90^{\circ}$. Such a zonal asymmetry of the MSE tendency causes the wave propagation toward the positive tendency gradient. Furthermore, it suggests a continuous and smooth eastward phase speed under this type of moisture mode theory.

The second type of the moisture mode emphasizes the role of zonal asymmetry of the perturbation moisture itself in the MJO eastward propagation ( $\mathrm{Hsu}$ and $\mathrm{Li}$ 2012). It was found that MJO-scale moisture was accumulated in the boundary layer to the east of the MJO convection. The accumulated boundary layer moisture further destabilizes atmosphere in the front through inducing convective instability, which is favorable for triggering shallow and congestus convection and then deep convection (e.g., Johnson et al. 1999; Kikuchi and 
Takayabu 2004; Liu et al. 2009; Jiang et al. 2011; Del Genio et al. 2012). Based on this argument, the movement of the $\mathrm{MJO}$ convective center is discontinuous as it jumps from the current existing convective center to a location to the east, with a characteristic horizontal length scale. As shown in the schematic diagram of Fig. 1b, the average eastward-propagation speed in this "jump" scenario is determined by the aforementioned length scale and a time scale for building up a new convection to the east of the preexisting convection.

While both the moisture mode theories above emphasized the importance of the perturbation moisture, the detailed phase evolution characteristics of the MJO convection may differ markedly. Motivated by the physical reasoning above, in the current study we intend to develop a novel method to illustrate the detailed phase evolution of the MJO based on observations and to reveal how theories can meet the reality. It is anticipated that such a comparison of detailed phase evolutions would give insight to the fundamental dynamics of MJO propagation.

The remaining part of this paper is organized as following. The data and method are introduced in section 2. The detailed daily evolution of maximum phases of the MJO is presented in section 3. The temporal and spatial scales associated with the MJO phase evolution are discussed in section 4. Sensitivity of the analysis result to a different longitudinal location is depicted in section 5 . Finally, conclusions and discussion are given in section 6.

\section{Data and methods}

The major datasets used in the current study include satellite measured daily outgoing longwave radiation (OLR) (Liebmann and Smith 1996), daily precipitation data from Global Precipitation Climatology Project, version 1.1 (GPCP; Huffman et al. 2001), and daily averaged European Centre for Medium-Range Weather Forecasts interim reanalysis (ERA-Interim) (Dee et al. 2011). The reanalysis data consist of three-dimensional wind, geopotential height, temperature and moisture fields at multiple constant pressure vertical levels ranged from 1000 to $100 \mathrm{hPa}$ with a 50-hPa interval. The current study covers the period of 1997-2015. Only the boreal winter season (November-April) was analyzed because this is the season with most pronounced eastwardpropagating MJO signals.

Before we introduce our method to illustrate the detailed phase evolution of the MJO, we first give an example of a real MJO case. Figure 2 shows the Hovmöller diagrams of the OLR anomaly [reconstructed by the real-time multivariate MJO (RMM) indices] averaged between $15^{\circ} \mathrm{S}$ and $15^{\circ} \mathrm{N}$ during November-December in 1979. The green line represents the estimated MJO

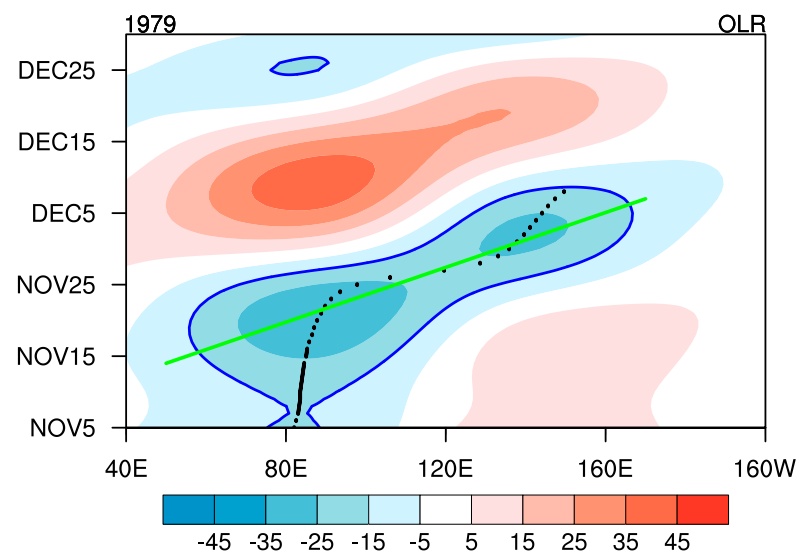

FIG. 2. Hovmöller diagrams of reconstructed OLR (by RMM index) averaged between $15^{\circ} \mathrm{S}$ and $15^{\circ} \mathrm{N}$ during NovemberDecember in 1979 . The blue contours indicate $-15 \mathrm{~W} \mathrm{~m}^{-2}$. The dots indicate the daily longitude of minimum OLR. The slope of the thick green line represents the phase speed of $5 \mathrm{~m} \mathrm{~s}^{-1}$.

phase slope by the traditional method (e.g., Wang and Rui 1990). It represents a "smooth" eastward-propagation feature from the eastern Indian Ocean to the western Pacific with an average phase speed of about $5 \mathrm{~ms}^{-1}$. A black dot in Fig. 2 denotes the location of the MJO center (or phase) at each day. It is interesting to note that the convective center stagnates for a few days at a longitudinal zone (near $80^{\circ} \mathrm{E}$ ) and then jumps into another longitudinal zone. Such phase evolution characteristic differs significantly from the green line. Therefore, it is necessary to investigate the detailed propagation feature of the MJO instead of using the traditional assessment method.

Considering that the original definition of "phase" is referred to the location and time of the maximum convective centers, a time normalization method is developed to reveal the maximum phase of MJO at each time lag. In this method, the lead-lag regressed field is normalized based on their amplitudes at each time lag. The equation form of this normalization could be written as

$$
\tilde{A}_{i, j}=\left[\frac{A_{i}}{\max \left|A_{i}\right|}\right]_{j},
$$

where $A$ represents lag-regressed column-integrated MSE or precipitation anomaly, $\tilde{A}$ represents the normalized result, $i$ denotes the longitude from $40^{\circ} \mathrm{E}$ to $180^{\circ}$ and $j$ denotes each lagged time. Through this normalization, the temporal evolution of MJO phases can be clearly illustrated.

Figure 3 compares the results obtained from a conventional assessment method (i.e., lead-lag regression) and the time normalization method. Figure 3 a shows the time-longitude diagrams of the intraseasonal precipitation and column-integrated $\operatorname{MSE}$ (hereafter $\langle m\rangle$ ) 


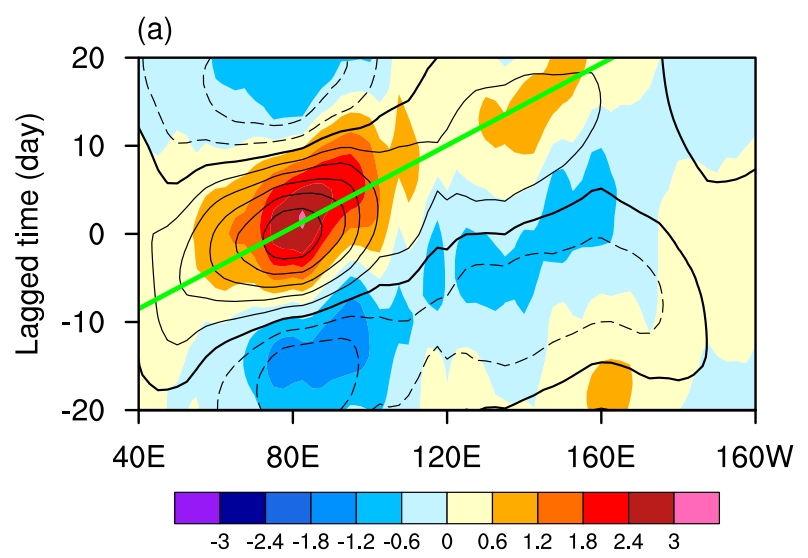

(b)

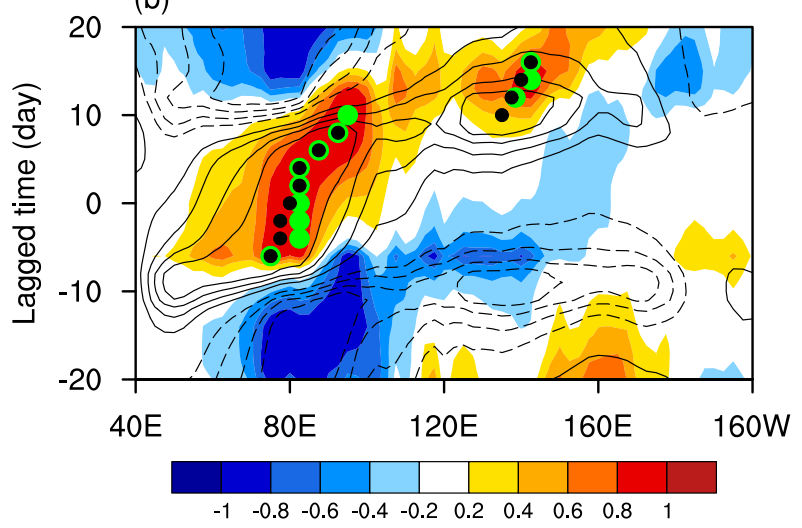

FIG. 3. (a) Time-longitude diagrams of lag-regressed precipitation anomaly (shaded; $\mathrm{mm} \mathrm{day}^{-1}$ ) and column-integrated MSE anomaly (contours with an interval of $1.5 \times 10^{6} \mathrm{~J} \mathrm{~m}^{-2}$; negative values are dashed) along the equator relative to the standardized time series of 20-100-day filtered column-integrated MSE anomaly at the eastern Indian Ocean $\left(5^{\circ} \mathrm{S}-5^{\circ} \mathrm{N}, 75^{\circ}-85^{\circ} \mathrm{E}\right)$. The slope of the green thick line denotes the phase speed of $5 \mathrm{~m} \mathrm{~s}^{-1}$. (b) As in (a), except that the lag-regressed fields are normalized by the maximum absolute value at each time lag. The centers of positive column-integrated MSE (precipitation) anomalies from day -6 to day 16 with an interval of two days are marked by black (green) dots.

anomalies regressed to a reference time series of the 20-100-day filtered $\langle m\rangle$ averaged over the eastern equatorial Indian Ocean $\left(5^{\circ} \mathrm{S}-5^{\circ} \mathrm{N}, 75^{\circ}-85^{\circ} \mathrm{E}\right)$. It shows that both the precipitation and MSE anomalies exhibit in general a "smooth" eastward-propagation feature, as indicated by the green line. Figure $3 \mathrm{~b}$ shows the phase evolution diagrams after applying the time normalization method. The black and green dots represent actual maximum centers at each time level. Obviously, it illustrates a distinctive evolution characteristic in both the precipitation and $\langle m\rangle$ anomaly fields. We will discuss the detailed evolution characteristics in the subsequent section. Similar features are found when a 20-100-day filtered precipitation anomaly is used as the reference time series. We also apply the same normalization method to the intraseasonal OLR field, and a similar phase evolution characteristic is found (figures not shown).

\section{Evolution of maximum phase of the MJO}

In this section we focus on examining the MJO phase evolution with the reference point in the equatorial eastern Indian Ocean $\left(75^{\circ}-85^{\circ} \mathrm{E}, 5^{\circ} \mathrm{S}-5^{\circ} \mathrm{N}\right)$, one of most active regions of MJO. While the conventional analysis (Fig. 3a) shows the "smooth" eastward propagation along the equator in both the precipitation and $\langle m\rangle$ anomaly fields, the new analysis method reproduces a very different evolution characteristic. One may roughly estimate the MJO propagation speed based on Fig. 3a. For example, the MJO-scale precipitation anomaly and $\langle m\rangle$ anomaly move roughly for a $50^{\circ}$ longitude within 10 days (from the Indian Ocean to the western Pacific), which corresponds to an average phase speed of about $5 \mathrm{~m} \mathrm{~s}^{-1}$. This estimated propagation speed is consistent with many previous studies (e.g., Wang et al. 2017). However, because the lagged regression analysis result always projects the largest amplitude near the reference longitude, the detailed longitudinal locations of the maximum convective phases are not clearly seen.

As stated in section 2, to better track the MJO phase propagation, we normalize the perturbation based on its amplitude at each time lag. As shown in Fig. 3b, the seemingly smooth propagation shown in Fig. 3a is now changed to a discontinuous propagation, and the overall MJO evolution is now separated into two temporal stages. In the first stage (day 0-10), the MJO peak phases are confined over the original convective region (around $80^{\circ}-100^{\circ} \mathrm{E}$ ). In the second stage, the MJO peak phases jump into the longitudinal band of $140^{\circ}-150^{\circ} \mathrm{E}$ and stay there during the subsequent 10 days (day 10-20). Therefore, the phase diagram in Fig. $3 b$ clearly illustrates a sudden jump evolution characteristic of MJO.

The normalized phase diagrams indicate clearly that the MJO phase does not move smoothly, rather it jumps. To better reveal the phase evolution characteristic, we examine the longitudinal profiles of the regressed $\langle m\rangle$ anomalies along the equator at each time lag from day 0 to 18 . As shown in Fig. 4a, the $\langle m\rangle$ anomaly peaks at $80^{\circ} \mathrm{E}$ at day 0 and stays in the longitudinal zone of $80^{\circ}-$ $90^{\circ} \mathrm{E}$ as its amplitude decays. At day 6 , a second center of the $\langle m\rangle$ anomaly emerges and develops near $140^{\circ} \mathrm{E}$. At day 9 , the newly developed $\langle m\rangle$ anomaly center at $140^{\circ} \mathrm{E}$ becomes the maximum center on that day, signifying a jump of the $\mathrm{MJO}$ center from $80^{\circ}-90^{\circ} \mathrm{E}$ to $140^{\circ} \mathrm{E}$. This phase jump is consistent with the feature shown in Fig. 3b.

We further examine the phase evolutions of other fields in Figs. 4b-4f. The variables examined here include OLR, 
(a) $<$ m $>$

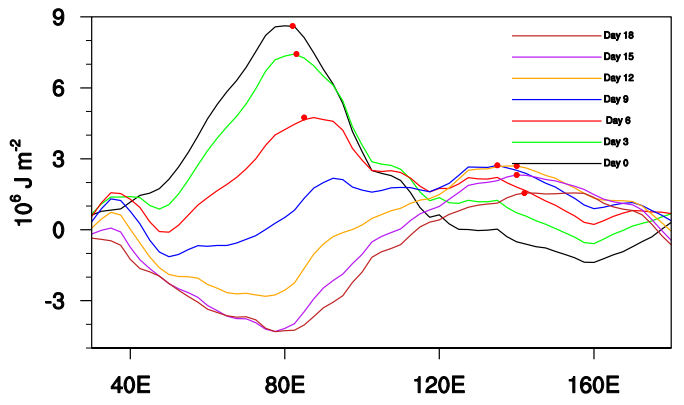

(c) precipitation

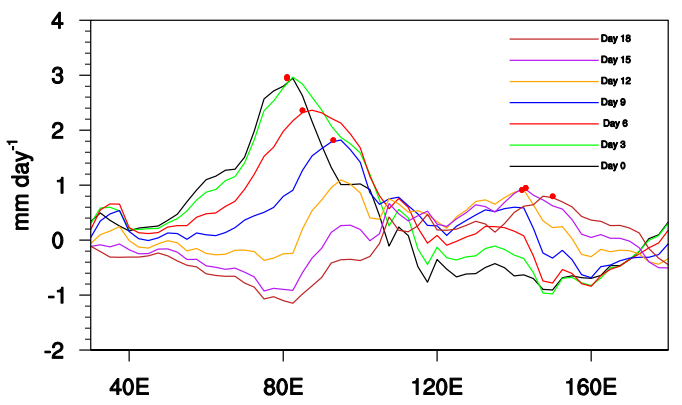

(e) omega

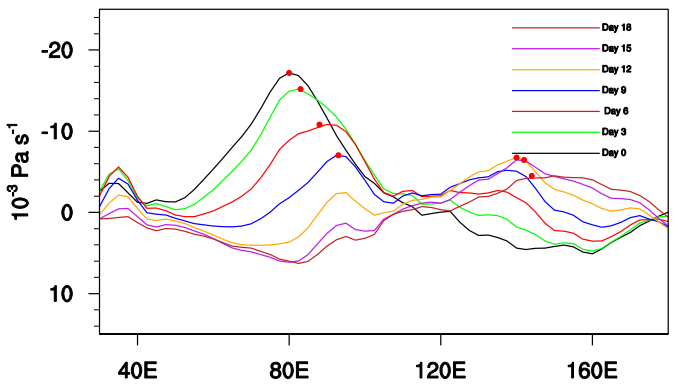

(b) OLR

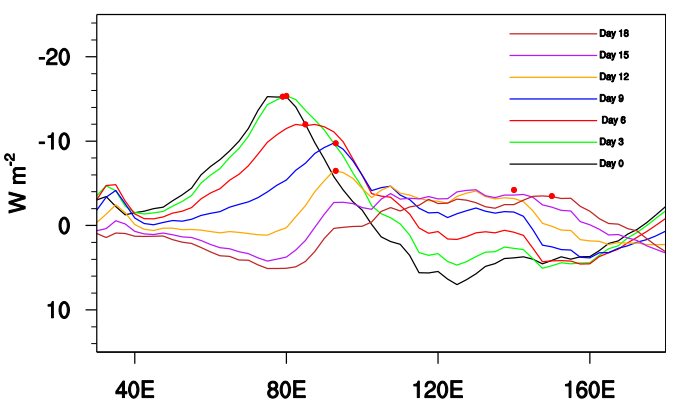

(d) Q2

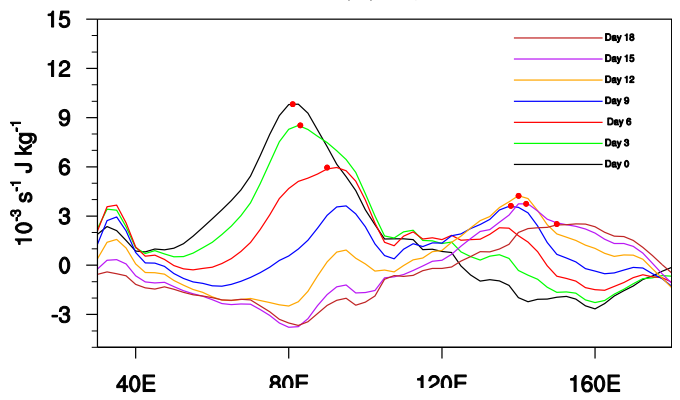

(f) Q1

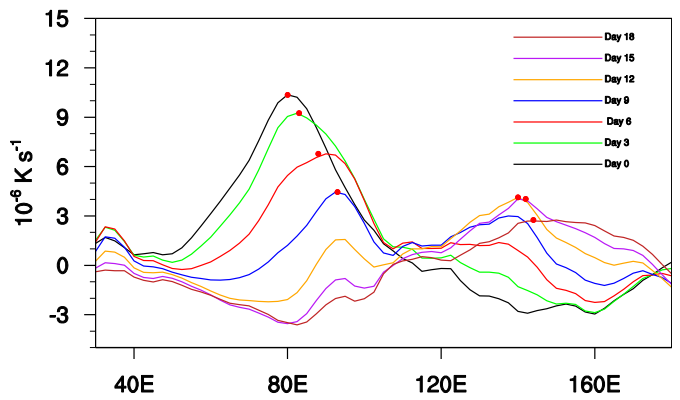

FIG. 4. Zonal profiles of lag-regressed fields of different variables along the equator at day 0 (black curve), day 3 (green curve), day 6 (red curve), day 9 (blue curve), day 12 (orange curve), day 15 (purple curve), and day 18 (brown curve). The regressed fields include (a) column-integrated MSE anomaly $\left(10^{6} \mathrm{~J} \mathrm{~m}^{-2}\right)$, (b) OLR anomaly ( $\left.\mathrm{W} \mathrm{m}^{-2}\right)$, (c) precipitation anomaly $\left(\mathrm{mm} \mathrm{day}^{-1}\right)$, and $900-100-\mathrm{hPa}$ averaged (d) $Q_{2}$ anomaly $\left(10^{-3} \mathrm{~s}^{-1} \mathrm{~J} \mathrm{~kg}^{-1}\right)$, (e) pressure velocity anomaly $\left(10^{-3} \mathrm{~Pa} \mathrm{~s}^{-1}\right)$, and (f) $Q_{1}$ anomaly $\left(10^{-6} \mathrm{~K} \mathrm{~s}^{-1}\right)$. The reference time series is standardized time series of 20-100-day filtered column-integrated MSE anomaly at the eastern Indian Ocean $\left(5^{\circ} \mathrm{S}-5^{\circ} \mathrm{N}, 75^{\circ}-85^{\circ} \mathrm{E}\right)$. The peak of regressed field of each variable at each day is marked by a red dot.

precipitation, 900-100-hPa-averaged pressure velocity, 900-100-hPa-averaged diabatic heating (i.e., $Q_{1}$ ) and 900-100-hPa-averaged moisture sink (i.e., $Q_{2}$ ) anomaly fields. The phase evolutions of these variables are all very similar to that of $\langle m\rangle$, except that the timing of the jump may shift a couple of days. The overall transitional time for the jump happens at around day 10. All these results above suggest that different from the conventional view of a "smooth" MJO eastward propagation, MJO phase evolution is characterized by a zonal jump. Such a jumping feature is closely related to the fact that congestus clouds and new convection develop to the east of preexisting MJO deep convection as the old convection weakens.

\section{Factors determining the length and temporal scales of the jump}

Figures 3 and 4 show that the horizontal length and temporal scales of the jump are about $50^{\circ}$ in longitude and 10 days. To understand the factors that determine the preferred length and temporal scales, we further examine the vertical and horizontal structures of the MJO. Figure 5 displays the longitude-vertical diagrams 

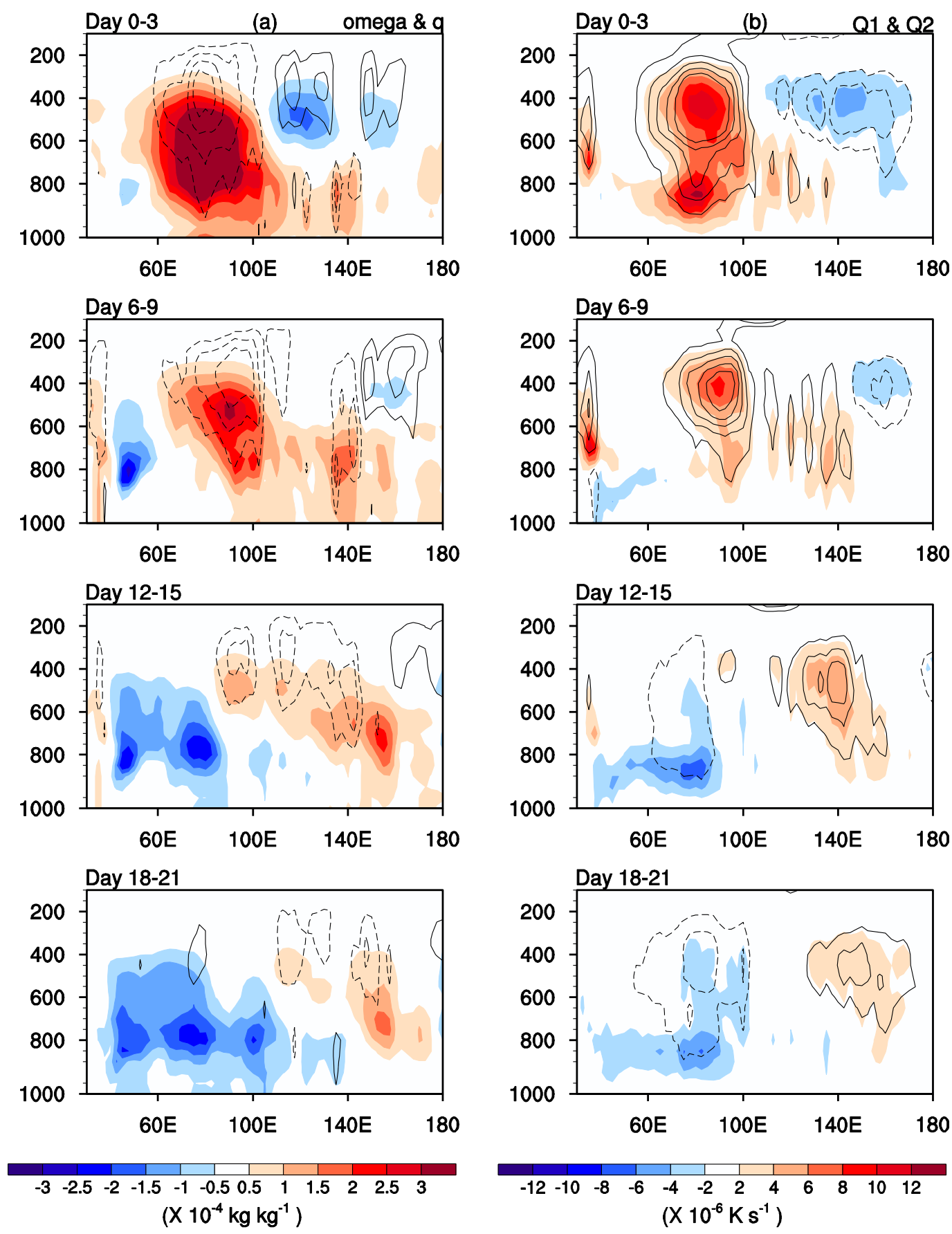

FIG. 5. (a) Longitude-vertical diagrams of lag-regressed pressure velocity anomaly (contours; $10^{-3} \mathrm{~Pa} \mathrm{~s}^{-1}$ ) and specific humidity anomaly (shaded; $10^{-4} \mathrm{~kg} \mathrm{~kg}^{-1}$ ) along the equator. The panels from top to bottom represent the results averaged over days $0-3,6-9,12-15$ and $18-21$, respectively. The reference time series is standardized time series of 20-100-day filtered column-integrated MSE anomaly at the eastern Indian Ocean $\left(5^{\circ} \mathrm{S}-5^{\circ} \mathrm{N}, 75^{\circ}-85^{\circ} \mathrm{E}\right)$. (b) As in (a), but for the $Q_{1}$ anomaly (contours; $10^{-6} \mathrm{~K} \mathrm{~s}^{-1}$ ) and $Q_{2}$ anomaly (shaded; $10^{-3} \mathrm{~s}^{-1} \mathrm{~J} \mathrm{~kg}^{-1}$ ).

of lag-regressed pressure velocity, moisture, $Q_{1}$, and $Q_{2}$ anomalies along the equator over time. The day $0-3$ averaged result shows that the strongest ascending motion anomaly and positive $Q_{1}$ anomaly are seen near $80^{\circ} \mathrm{E}$ with their center at the middle troposphere (around $400 \mathrm{hPa}$ ), while abundant moisture is confined in the middle and lower troposphere near $80^{\circ} \mathrm{E}$ and $Q_{2}$ anomaly shows two centers, one is at $400 \mathrm{hPa}$ and the other is near $800 \mathrm{hPa}$. 

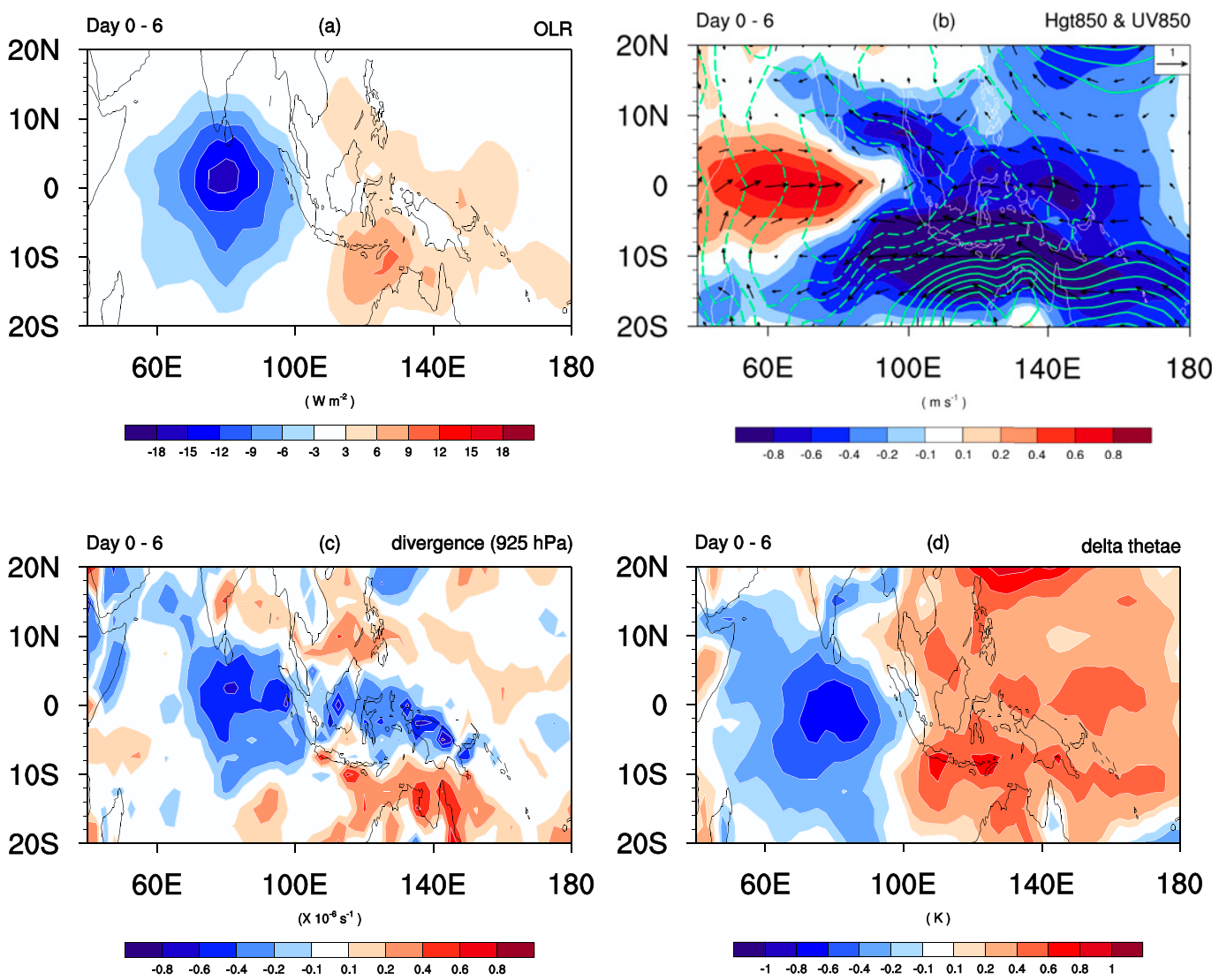

FIG. 6. (a) Lag-regressed OLR (shaded; $\mathrm{W} \mathrm{m}^{-2}$ ) anomaly averaged over days $0-6$. The reference time series is standardized time series of 20-100-day filtered column-integrated MSE anomaly at the eastern Indian Ocean $\left(5^{\circ} \mathrm{S}-\right.$ $5^{\circ} \mathrm{N}, 75^{\circ}-85^{\circ} \mathrm{E}$ ). (b) As in (a), but for geopotential height (contour; $\mathrm{m}^{2} \mathrm{~s}^{-2}$ ), wind (vectors; $\mathrm{m} \mathrm{s}^{-1}$ ), and zonal wind (shaded; $\mathrm{m} \mathrm{s}^{-1}$ ) anomalies at $850 \mathrm{hPa}$. (c) As in (a), but for the divergence anomaly at $925 \mathrm{hPa}$. (d) As in (a), but for the convective instability anomaly $(\mathrm{K})$, which is calculated as the difference of $\theta_{e}$ at the boundary layer and the middle troposphere (i.e., 1000-850-hPa average minus 500-400-hPa average).

At the same time, there are obvious descending motion anomalies and negative diabatic heating anomalies in the upper troposphere near $140^{\circ} \mathrm{E}$, where relatively weak positive moisture anomalies and ascending motion anomalies are shown in the boundary layer. This is consistent with many previous studies (e.g., Wang et al. 2017). The day 6-9 average indicates that the intensity of each variable near $80^{\circ} \mathrm{E}$ was significantly weakened and shifted eastward slightly, and the boundary layer ascending motion anomaly and positive moisture anomaly are increased near $140^{\circ} \mathrm{E}$. By day $12-15$, a strong ascending motion anomaly and positive $Q_{1}, Q_{2}$, and moisture anomalies are clearly shown near $140^{\circ} \mathrm{E}$, while $80^{\circ} \mathrm{E}$ exhibits descending motion anomaly. During day 18-21, the main body of the MJO convection is still confined near $140^{\circ} \mathrm{E}$.

Then, why is the new convection induced near $140^{\circ} \mathrm{E}$ ? Fig. 6 shows the horizontal distributions of some lagregressed fields averaged over day $0-6$, when the main body of the $\mathrm{MJO}$ convection is confined near $80^{\circ} \mathrm{E}$ (see Fig. 6a). As shown in Fig. 6b, easterly anomaly is to the east of the convective center and westerly anomaly is to the west in the lower troposphere, and low pressure anomalies are at the convective center and extend eastward. Note that the strongest easterly wind at the equator is located near $140^{\circ} \mathrm{E}$. This indicates that the Kelvin wave response is maximum at $140^{\circ} \mathrm{E}$. The divergence field at $925 \mathrm{hPa}$ shows that maximum convergence appears at the deep convective region and near $140^{\circ} \mathrm{E}$ (see Fig. $6 \mathrm{c}$ ), which is attributed to the forcing of a low pressure anomaly at the top of the boundary layer (Hsu and Li 2012). Figure 6d displays the horizontal distribution of the convective instability index, which is calculated as the difference of $\theta_{e}$ at the boundary layer and the middle troposphere (i.e., 1000-850-hPa average minus $500-400-\mathrm{hPa}$ average). It shows an obvious zonal dipole type and the positive anomaly region near $140^{\circ} \mathrm{E}$ indicates that this area is convectively unstable. 
(a) $<$ m $>$

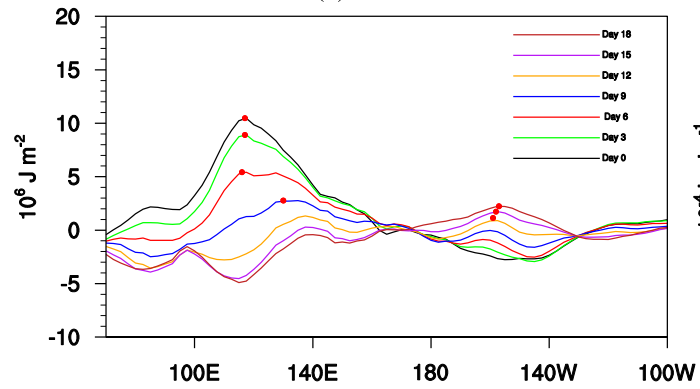

(c) omega

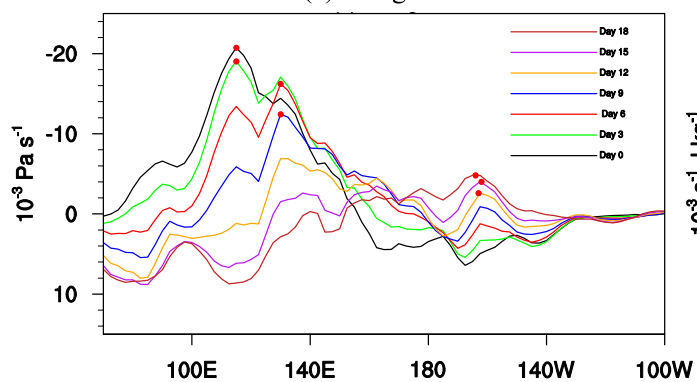

(b) specific humidity

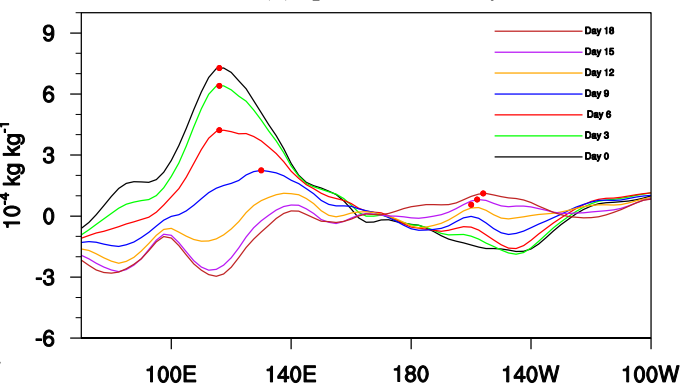

(d) Q2

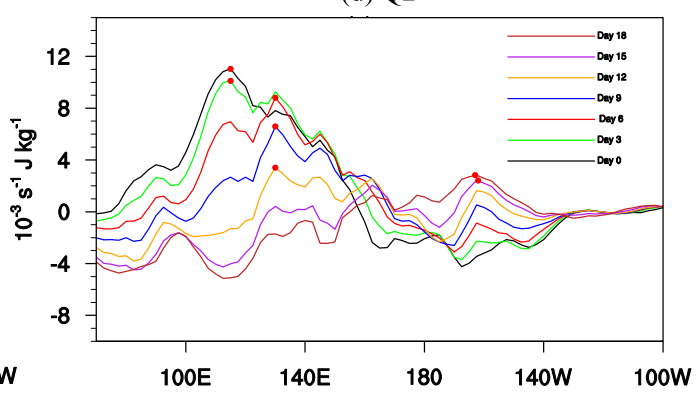

FIG. 7. Zonal profiles of lag-regressed fields of different variables along $10^{\circ} \mathrm{S}$ at days 0 (black curve), 3 (green curve), 6 (red curve), 9 (blue curve), 12 (orange curve), 15 (purple curve), and 18 (brown curve). The regressed fields include (a) column-integrated MSE anomaly $\left(10^{6} \mathrm{~J} \mathrm{~m}^{-2}\right)$ and $900-100-\mathrm{hPa}$ averaged (b) specific humidity anomaly $\left(10^{-4} \mathrm{~kg} \mathrm{~kg}^{-1}\right)$, (c) pressure velocity anomaly $\left(10^{-3} \mathrm{~Pa} \mathrm{~s}^{-1}\right)$, and (d) $Q_{2}$ anomaly $\left(\mathrm{J} \mathrm{kg}^{-1}\right)$. The reference time series is standardized time series of 20-100-day filtered column-integrated MSE anomaly at the western Pacific $\left(15^{\circ}-5^{\circ} \mathrm{S}, 115^{\circ}-125^{\circ} \mathrm{E}\right)$. The peak of regressed field of each variable at each day is marked by a red dot.

The results above clearly show that when the MJO deep convection is still near $80^{\circ} \mathrm{E}$, water vapor has started to accumulate near $140^{\circ} \mathrm{E}$, and convective instability is being built up, which is conducive to the development of new convection in situ. The distance between the old and new convection is determined by the Kelvin wave response.

It has been shown that the low pressure anomaly associated with the Kelvin wave response can induce a boundary layer convergence anomaly and associated ascending motion in the front of the MJO convection (Hsu and Li 2012). The ascending anomaly further increases the perturbation moisture through anomalous vertical advection, favoring the development of unstable stratification (Li 2014). Such argument will be further demonstrated through a boundary layer moisture budget analysis in the next section.

Thus, the time scale of 10 days inferred from Figs. 3 and 4 represents the period in which the atmospheric boundary layer moistens and the unstable stratification sets up. It is the combined effect of the characteristic zonal distance determined by the Kelvin wave response $(\sim 5000 \mathrm{~km})$ and the characteristic time scale $(\sim 10$ day) related to the lower-tropospheric moistening and instability that determines the averaged phase speed of about $5^{\circ}$ per day, as crudely estimated by Fig. 3a.

\section{Sensitivity of MJO phase evolution to longitudinal location}

To investigate how sensitive the phase evolution is to a different MJO location, in this section we examine the evolution characteristics of several key variables at a reference point in the western Pacific $\left(120^{\circ} \mathrm{E}\right)$. Considering the fact that the MJO convection always shifts southward over the Maritime Continent region (Zhao et al. 2013), the reference box is selected at $\left(115^{\circ}-\right.$ $\left.125^{\circ} \mathrm{E}, 15^{\circ}-5^{\circ} \mathrm{S}\right)$. The following analysis are the same as before, except that the reference time series is the 20-100 day filtered $\langle m\rangle$ anomaly averaged over $\left(115^{\circ}-125^{\circ} \mathrm{E}, 15^{\circ}-5^{\circ} \mathrm{S}\right)$. Figure 7 shows the zonal profiles of lag-regressed several variables that are closely related to the main body of MJO convection along the target latitude (i.e., $10^{\circ} \mathrm{S}$ ) over time. The selected variables include $\langle m\rangle$, 900-100-hPa-averaged moisture, 900-100$\mathrm{hPa}$-averaged pressure velocity, and 900-100-hPa-averaged $Q_{2}$. According to Fig. 7a, the positive $\langle m\rangle$ peaks in the vicinity of $120^{\circ} \mathrm{E}$ from day 0 to 9 , although its position shifts slightly eastward over time. Meanwhile, the 

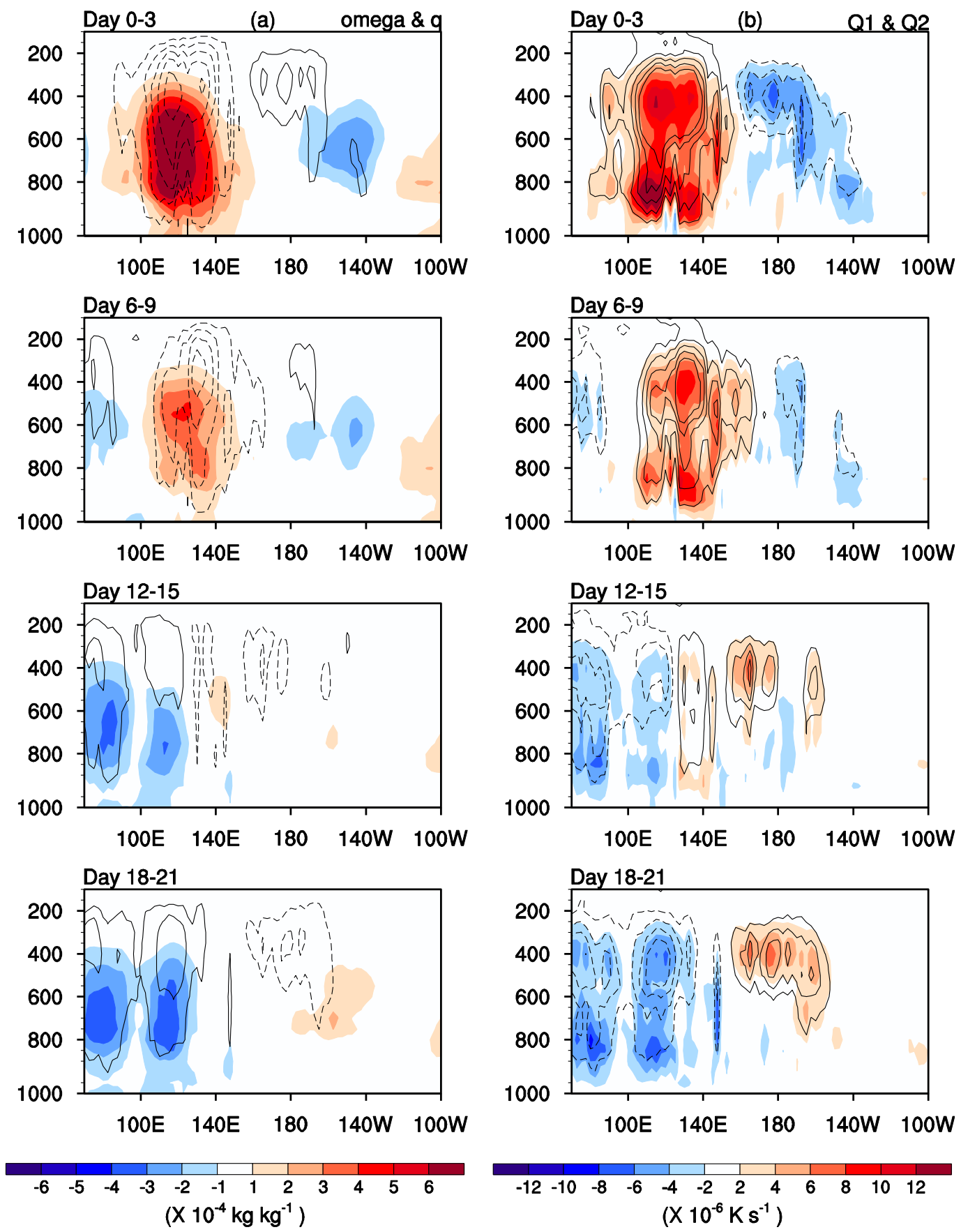

FIG. 8. As in Fig. 5, except that the reference time series is derived from the western Pacific $\left(15^{\circ}-5^{\circ} \mathrm{S}, 115^{\circ}-125^{\circ} \mathrm{E}\right)$ and the regressed fields are along $10^{\circ} \mathrm{S}$.

amplitude of $\langle m\rangle$ anomaly continuously increases between $180^{\circ}$ and $140^{\circ} \mathrm{W}$, while it constantly weakens near $120^{\circ} \mathrm{E}$. At day 12 , the positive peak appears near $160^{\circ} \mathrm{W}$ and stays there until day 18 . The results of the other variables are similar, except that the change in the peak position of some variables occurs at day 15 . The above results suggest that the eastward propagation of the main body of $\mathrm{MJO}$ convection near $120^{\circ} \mathrm{E}$ is due to a sudden jump at day 12-15. This result is consistent with that for MJO convection at $80^{\circ} \mathrm{E}$.

Figure 8 further shows the evolutions of longitudevertical diagrams of different variables. During day $0-3$, there are strong ascending motion anomalies and positive $Q_{1}$ in the middle troposphere near $120^{\circ} \mathrm{E}$, and abundant 
moisture in the lower and middle troposphere. The $Q_{2}$ near $120^{\circ} \mathrm{E}$ has two positive centers: one is at upper troposphere and the other is at the boundary layer. At the same time, there are obvious descending motion anomalies and negative diabatic heating anomalies to the east, where relatively weak positive moisture anomalies are observed in the boundary layer. During days $6-15$, the intensity of the variables near $120^{\circ} \mathrm{E}$ weaken gradually. By days 18-21, significant ascending motion, positive moisture, $Q_{1}$, and $Q_{2}$ anomalies are seen between $180^{\circ}$ and $140^{\circ} \mathrm{W}$, while descending motion anomalies appear near $120^{\circ} \mathrm{E}$. It indicates that the main body of $\mathrm{MJO}$ convection jumps to the vicinity of $180^{\circ}-140^{\circ} \mathrm{W}$. Then, the convective center is stable between $180^{\circ}$ and $140^{\circ} \mathrm{W}$ (figure not shown).

Why does the new convection occur between $180^{\circ}$ and $140^{\circ} \mathrm{W}$ ? Similar to the previous analysis, Fig. 9 shows the horizontal distributions of different variables averaged over day $0-6$, when the main body of MJO convection is near $120^{\circ} \mathrm{E}$ (Fig. 9a). Note that the tick marks in the $y$ axis indicate the relative latitudes in regard of the target latitude (i.e., $10^{\circ} \mathrm{S}$ ). As shown in Fig. 9b, easterly wind is to the east of the convective center, showing the Kelvin wave response to the convection. Further, the maximum center of the easterly anomaly on the target latitude is between $180^{\circ}$ and $140^{\circ} \mathrm{W}$, indicating that the maximum response of the Kelvin wave occurs between $180^{\circ}$ and $140^{\circ} \mathrm{W}$. The horizontal distribution of the convective instability index shows a clear zonal dipole type, and the positive anomaly region between $180^{\circ}$ and $140^{\circ} \mathrm{W}$ indicates that this area is convectively unstable and is conducive to the development of new convection (Fig. 9c).

To clearly understand the mechanism for the zonal asymmetric distribution of the boundary layer moisture relative to the MJO convective center or the setup of the atmospheric convective instability in the leading edge, we conducted a boundary layer moisture budget analysis over the moistening region ahead of the MJO convective center. For the $\mathrm{MJO}$ center at $80^{\circ} \mathrm{E}$, the budget result shows that the moistening over the region of $130^{\circ}-$ $150^{\circ} \mathrm{E}, 5^{\circ}-5^{\circ} \mathrm{N}$ is mainly contributed by the vertical moisture advection term, while the moisture source term $\left(Q_{2}\right)$, including condensational heating and surface latent heat flux, has a negative contribution (Fig. 10a). This is in contrast with the budget result when MJO center is at $120^{\circ} \mathrm{E}$ (Fig. 10b), which indicates that the moistening is attributed to the moisture source term while the vertical advection contributes negatively.

While the result above implies a reversed latent heat flux effect at the two MJO centers, Fig. 11 shows a direct evidence of the surface latent heat flux anomaly for MJO centers at $80^{\circ}$ and $120^{\circ} \mathrm{E}$. For the MJO center at
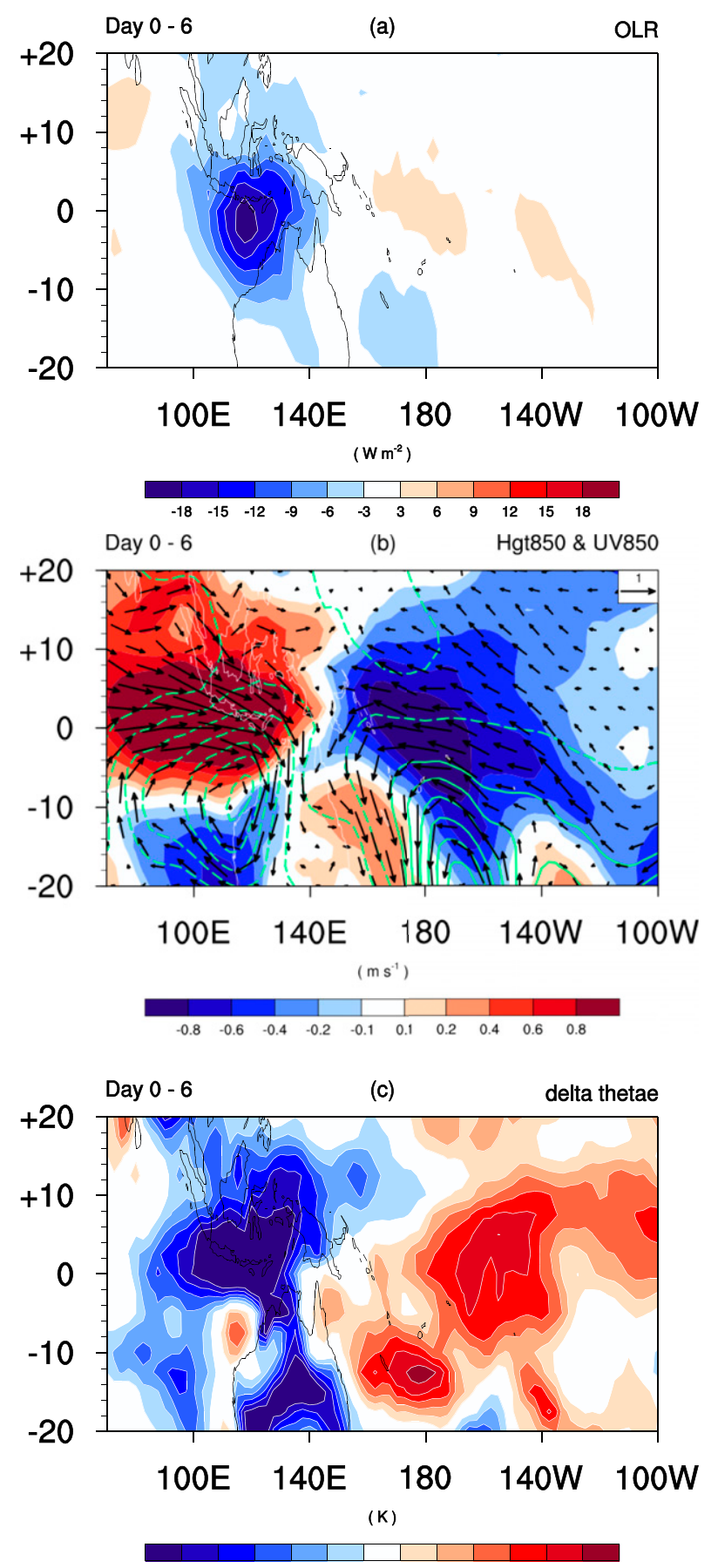

$\begin{array}{cccccccccccc}-0.6 & -0.5 & -0.4 & -0.3 & -0.2 & -0.1 & 0.1 & 0.2 & 0.3 & 0.4 & 0.5 & 0.6\end{array}$

FIG. 9. (a) Lag-regressed OLR (shaded; $\mathrm{W} \mathrm{m}^{-2}$ ) anomaly averaged from day 0 to 6 . The reference time series is standardized time series of 20-100-day filtered column-integrated MSE anomaly at the western Pacific $\left(15^{\circ}-5^{\circ} \mathrm{S}, 115^{\circ}-125^{\circ} \mathrm{E}\right)$. (b) As in (a), but for geopotential height (contours; $\mathrm{m}^{2} \mathrm{~s}^{-2}$ ), wind (vectors; $\mathrm{m} \mathrm{s}^{-1}$ ), and zonal wind (shaded; $\mathrm{m} \mathrm{s}^{-1}$ ) anomalies at $850 \mathrm{hPa}$. (c) As in (a), but for the convective instability anomaly $(\mathrm{K})$. 

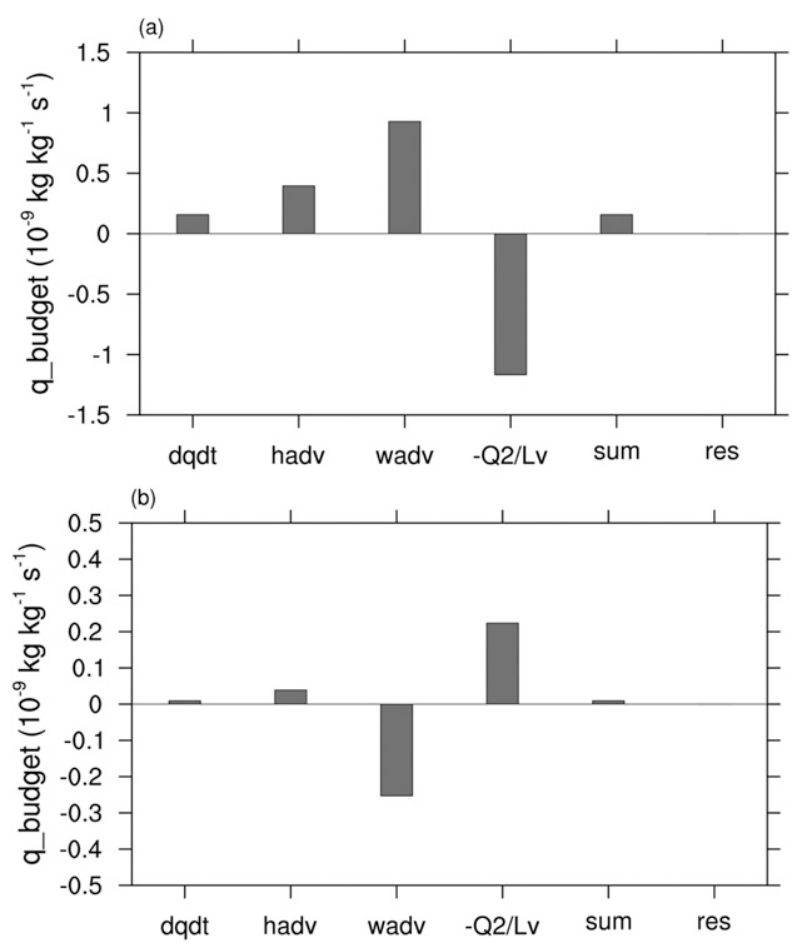

FIG. 10. (a) 1000-700-hPa integrated intraseasonal moisture budget terms $\left(10^{-9} \mathrm{~kg} \mathrm{~kg}^{-1} \mathrm{~s}^{-1}\right)$ over the moistening region of $130^{\circ}-150^{\circ} \mathrm{E}, 5^{\circ} \mathrm{S}-5^{\circ} \mathrm{N}$ averaged from day 0 to 6 for the MJO center at $80^{\circ} \mathrm{E}$. From left to right, the bars are observed specific humidity tendency, horizontal moisture advection, vertical moisture advection, moisture sink term, sum of the horizontal and vertical advection and the moisture sink term, and the residual term. (b) As in (a), but for the moisture budget over $180^{\circ}-140^{\circ} \mathrm{W}, 15^{\circ}-5^{\circ} \mathrm{S}$ for the $\mathrm{MJO}$ center at $120^{\circ} \mathrm{E}$.

$80^{\circ} \mathrm{E}$, a negative surface latent heat flux anomaly (or less surface evaporation) appears over $100^{\circ}-170^{\circ} \mathrm{E}$ (Fig. 11a), resulted from reduced wind speed due to the superposition of MJO-induced easterly anomaly and the mean westerly over the equatorial western Pacific (Fig. 11b). For the MJO center at $120^{\circ} \mathrm{E}$, a positive surface latent heat flux anomaly occurs east of $180^{\circ}$ (Fig. 11c), due to wind speed increase resulted from the superposition of MJO-induced easterly and the mean easterly over the eastern Pacific Ocean (Fig. 11d).

The analysis above suggests a longitudinal-locationdependent wind-induced surface heat exchange (i.e., WISHE) process, that is, for MJO in the eastern Indian Ocean, the moistening in front of the MJO convection arises from vertical advection, whereas for MJO over the central Maritime Continent, the moistening is attributed to the surface evaporating process. The latter suggests the possible role of the WISHE mechanism in promoting the MJO eastward propagation (Emanuel 2020; Fuchs and Raymond 2017).

\section{Summary and discussion}

Understanding the eastward propagation of the MJO has been a challenge to theoretical studies and modelers for years. A recent widely accepted theory considers the MJO as a "moisture" mode, as the column integrated moisture or MSE anomaly is approximately in phase with the MJO-scale precipitation anomaly. There are two schools of thinking under the moisture mode theory. One school (e.g., Sobel and Maloney 2013; Adames and Kim 2016) emphasizes that the anomalous MSE center and the MJO convective center are in phase, so the convection propagation is attributed to the zonal asymmetry of the MSE tendency - a positive MSE tendency to the east and a negative MSE tendency to the west of the MJO convection. Therefore, such a process could be described using a simple one-dimensional advection equation whose solution is a constant eastwardpropagating wave. In this scenario, a continuous and smooth phase propagation speed would be induced. The zonal asymmetry of the boundary layer moisture anomaly is not considered in this theory. The other school (Hsu and Li 2012) emphasizes that while the maximum moisture anomaly in the middle troposphere is in phase with the MJO convection, the boundary layer moisture anomaly leads the convective center. Therefore, the eastward movement arises from the zonal asymmetry of the boundary layer moisture center relative the MJO convective center, whereas the zonal asymmetry of MSE tendency is not considered. Such a process cannot be simply represented by the advection equation. The second type of the moisture mode theory implies that the propagation of $\mathrm{MJO}$ convection is discontinuous and may have a sudden jump during its eastward journey.

Motivated by the argument above, we intend to reveal the detailed evolution characteristics of MJO using a new analysis method, by normalizing the MJO perturbation at each time lag (i.e., time normalization method). The adopted normalization method is to "remove" the impact of amplitude change so that one could focus on the evolution of maximum phases of the MJO convection at each time level. It is found that whereas the conventional lagged regression maps illustrate a smooth eastwardpropagating MJO signal in both the precipitation and column-integrated MSE anomaly fields (Fig. 3a), the new method reproduces a distinctive MJO evolution characteristic (Fig. 3b). The temporal evolution of phase of MJO convection can be separated into two stages. In the first stage the MJO peak phases are confined over the original convective region (say, around $80^{\circ}-90^{\circ} \mathrm{E}$ ). In the second stage, the MJO peak phases jump into the longitudinal band east of the original convective region (around $140^{\circ}-$ $150^{\circ} \mathrm{E}$ ) and stay there during the subsequent 10-day 
EIO MJO
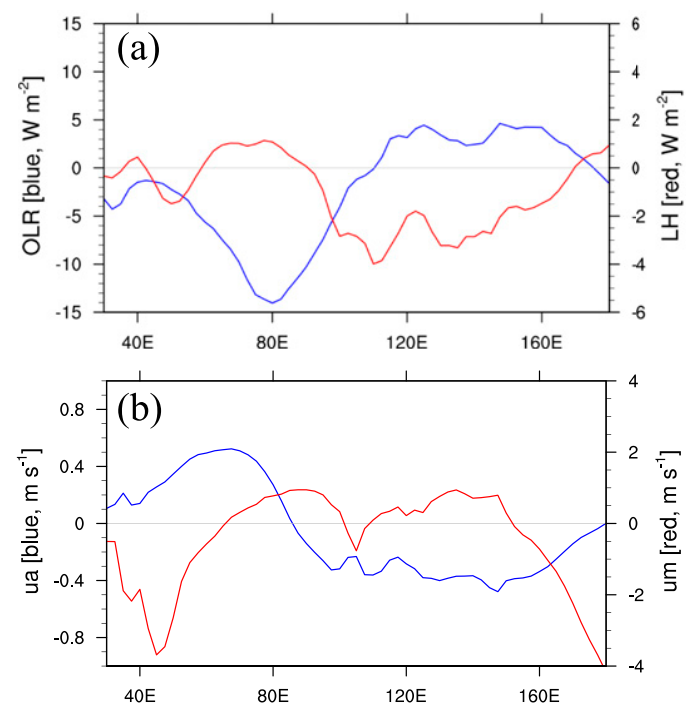

WP MJO
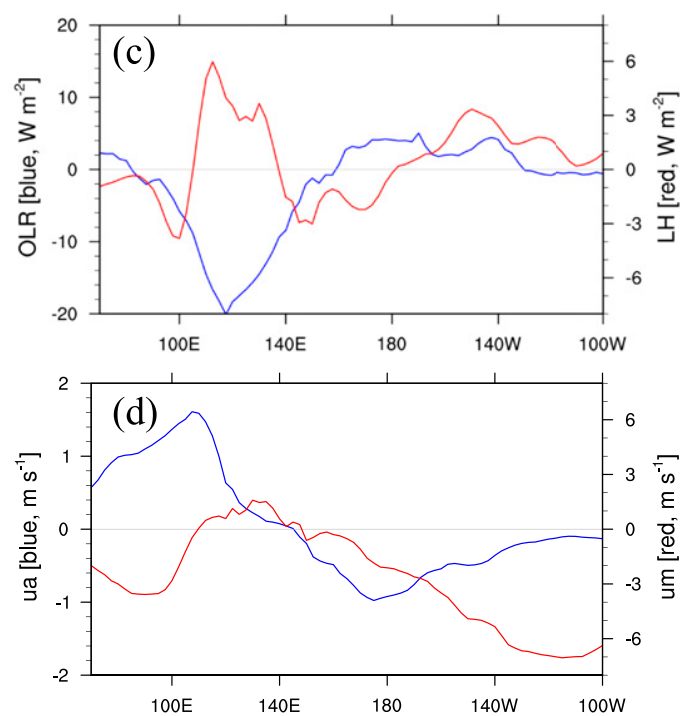

FIG. 11. Lag-regressed (a) OLR (blue; $\mathrm{W} \mathrm{m}^{-2}$ ) and surface latent heat flux (red; $\mathrm{W} \mathrm{m}^{-2}$ ) anomalies and (b) 1000$\mathrm{hPa}$ zonal wind (blue; $\mathrm{m} \mathrm{s}^{-1}$ ) anomaly along the equator averaged over days $0-6$. The reference time series is the standardized time series of 20-100-day filtered column-integrated MSE anomaly at the eastern Indian Ocean $\left(5^{\circ} \mathrm{S}-\right.$ $5^{\circ} \mathrm{N}, 75^{\circ}-85^{\circ} \mathrm{E}$ ). The red curve in (b) denotes the November-April mean 1000-hPa zonal wind ( $\left.\mathrm{m} \mathrm{s}^{-1}\right)$. (c), (d) As in (a) and (b), but the profiles are along $10^{\circ} \mathrm{S}$, and the reference time series is at the western Pacific Ocean $\left(15^{\circ}-5^{\circ} \mathrm{S}\right.$, $\left.115^{\circ}-125^{\circ} \mathrm{E}\right)$.

period. Therefore, the MJO convection does not move eastward smoothly, but jumps into a new location $5000 \mathrm{~km}$ east of the original convective center.

The discontinuous propagation characteristic of the MJO is found not only when the MJO is located over the Indian Ocean but also over the Maritime Continent/ western Pacific sector, suggesting that it is a general feature.

It is argued that the characteristic length scale of the jump is rooted in the heating-induced Kelvin wave response (Gill 1980; Li 2014; Wang et al. 2018), and the associated time scale is determined by the setup of an unstable stratification in the front of the MJO convection. The combined effect of the length and time scales determines the outcome of the average eastward phase speed.

A longitudinal-location-dependent premoistening mechanism is found based on a boundary layer moisture budget analysis. For the MJO in the eastern Indian Ocean, the moistening in front of the MJO convection arises from vertical advection, whereas for the MJO over the western Pacific Ocean, the moistening is attributed to the surface evaporating process. The latter suggests the possible role of the WISHE mechanism in promoting the MJO eastward propagation (Emanuel 2020; Fuchs and Raymond 2017).

One may wonder that why we use the time normalization method in the current study instead of a longitude normalization method to identify the maximum phase of the MJO convection. For an idealized MJO with a constant phase speed, the relationship between the moving distance and the time is linear. In this case, the results obtained from the time normalization and the longitude normalization methods should be exactly the same. However, assume the following idealized MJO scenario in which maximum OLR anomalies associated with MJO center stay in the same longitude (say, $80^{\circ} \mathrm{E}$ ) for 10 days (assume their amplitude is the same during the period), and after that the MJO center jumps into another longitude (say, $140^{\circ} \mathrm{E}$ ). In this scenario, the time normalization method is able to clearly identify the longitudinal locations of the MJO center at each time interval (i.e., each day). However, with the longitudinal normalization method, one may find difficulty to identify the exact time level of a maximum OLR anomaly at that longitude and any longitudinal grids between $80^{\circ}$ and $140^{\circ} \mathrm{E}$. This is why we used the time normalization method in the current analysis. We intend to further conduct a detailed comparison of the time and longitudinal normalization methods in future endeavors.

It is worth of mentioning that while the phase speed of the maximum convective centers shown in Fig. $3 \mathrm{~b}$ is slow in a certain location, the average phase speed over the Indo-western Pacific warm pool is similar to the green line in Fig. 3a. According to Fig. 3b, the moving distance of the maximum convective center from day -6 to +16 is about $80^{\circ}$ in longitude, showing an average speed of 
around $5 \mathrm{~m} \mathrm{~s}^{-1}$. Therefore, the current normalization method only shows a more detailed phase evolution but does not affect the average MJO propagation speed. And note that the longitudinal jump may be partially attributed to the mountain block and/or surface moisture condition, in addition to the internal atmospheric dynamics (such as heating induced Kelvin wave response) emphasized in the current manuscript, which needs further investigation.

The MJO detailed phase evolution characteristic illustrated by the current study suggests that the second type of the moisture mode theory (i.e., boundary layer moisture asymmetry) might be physically more reasonable, as the jumping feature shown in Figs. 2 and $3 b$ cannot be explained by the first type of the moisture mode theory, but could be well explained by the second type. It also suggests that the westward tilted vertical structure is critical for understanding MJO eastward propagation. It is worth mentioning that the current result does not necessarily oppose the first type of the moisture mode theory as the MSE tendency asymmetry is clearly presented in the observational diagnosis (e.g., Jiang et al. 2015; Wang et al. 2017). Given the complicated (non-sine) zonal distribution of the MSE tendency (Wang and Li 2020), the analogy to the linear advection equation is questionable. The purpose of the current study is not to deny the existing MSE tendency asymmetrybased moisture mode theory, rather to remind people how complex the maximum phases of MJO may involve with time.

Acknowledgments. L. Wang was supported by NSFC Grants 41975108, 41705059 and the Startup Foundation for Introducing Talent of NUIST. T. Li was supported by NSFC Grants 41875069, NSF Grant AGS-1643297, NOAA Grant NA18OAR4310298. This is SOEST Contribution 11103, IPRC Contribution 1461, and ESMC Contribution 316.

\section{REFERENCES}

Adames, Á. F., and D. Kim, 2016: The MJO as a dispersive, convectively coupled moisture wave: Theory and observations. J. Atmos. Sci., 73, 913-941, https://doi.org/10.1175/JAS-D-150170.1.

Chen, L., T. Li, S. K. Behera, and T. Doi, 2016a: Distinctive precursory air-sea signals between regular and super El Niños. Adv. Atmos. Sci., 33, 996-1004, https://doi.org/10.1007/s00376016-5250-8.

_ Y. Yu, and W. Zheng, 2016b: Improved ENSO simulation from climate system model FGOALS-g1.0 to FGOALS-g2. Climate Dyn., 47, 2617-2634, https://doi.org/10.1007/s00382-016-2988-8.

Cui, J., and T. Li, 2019: Changes of MJO propagation characteristics under global warming. Climate Dyn., 53, 5311-5327, https://doi.org/10.1007/s00382-019-04864-4.
Dee, D. P., and Coauthors, 2011: The ERA-Interim reanalysis: Configuration and performance of the data assimilation system. Quart. J. Roy. Meteor. Soc., 137, 553-597, https://doi.org/ 10.1002/qj.828.

Del Genio, A. D., Y. Chen, D. Kim, and M.-S. Yao, 2012: The MJO transition from shallow to deep convection in CloudSat CALIPSO data and GISS GCM simulations. J. Climate, 25, 3755-3770, https://doi.org/10.1175/JCLI-D-11-00384.1.

Emanuel, K., 2020: Slow modes of the equatorial waveguide. J. Atmos. Sci. 77, 1575-1582, https://doi.org/10.1175/JAS-D-19-0281.1.

Fuchs, Ž., and D. J. Raymond, 2017: A simple model of intraseasonal oscillations. J. Adv. Model. Earth Syst., 9, 1195-1211, https://doi.org/10.1002/2017MS000963.

Gill, A. E., 1980: Some simple solutions for heat-induced tropical circulation. Quart. J. Roy. Meteor. Soc., 106, 447-462, https:// doi.org/10.1002/qj.49710644905.

Hendon, H. H., and M. L. Salby, 1994: The life cycle of the MaddenJulian oscillation. J. Atmos. Sci., 51, 2225-2237, https://doi.org/ 10.1175/1520-0469(1994)051<2225:TLCOTM>2.0.CO;2.

Hsu, P., and T. Li, 2012: Role of the boundary layer moisture asymmetry in causing the eastward propagation of the Madden-Julian oscillation. J. Climate, 25, 4914-4931, https://doi.org/10.1175/ JCLI-D-11-00310.1.

Huffman, G. J., R. F. Adler, M. M. Morrissey, D. T. Bolvin, S. Curtis, R. Joyce, B. McGavock, and J. Susskind, 2001: Global precipitation at one-degree daily resolution from multisatellite observations. J. Hydrometeor., 2, 36-50, https:// doi.org/10.1175/1525-7541(2001)002<0036:gpaodd $>2.0$.co;2.

Jiang, X., and Coauthors, 2011: Vertical diabatic heating structure of the MJO: Intercomparison between recent reanalyses and TRMM estimates. Mon. Wea. Rev., 139, 3208-3223, https:// doi.org/10.1175/2011MWR3636.1.

, and Coauthors, 2015: Vertical structure and physical processes of the Madden-Julian oscillation: Exploring key model physics in climate simulations. J. Geophys. Res. Atmos., 120, 4718-4748, https://doi.org/10.1002/2014JD022375.

Johnson, R. H., T. M. Rickenbach, S. A. Rutledge, P. E. Ciesielski, and W. H. Schubert, 1999: Trimodal characteristics of tropical convection. J. Climate, 12, 2397-2418, https://doi.org/10.1175/ 1520-0442(1999)012<2397:TCOTC $>2.0$. CO;2.

Kessler, W. S., and R. Kleeman, 2000: Rectification of the Madden-Julian oscillation into the ENSO cycle. J. Climate, 13, 3560-3575, https://doi.org/10.1175/1520-0442(2000)013<3560: ROTMJO $>2.0 . \mathrm{CO} ; 2$.

Kikuchi, K., and Y. N. Takayabu, 2004: The development of organized convection associated with the MJO during TOGA COARE IOP: Trimodal characteristics. Geophys. Res. Lett., 31, L10101, https://doi.org/10.1029/2004GL019601.

Kim, D., and E. D. Maloney, 2017: Simulation of the MaddenJulian oscillation using general circulation models. The Global Monsoon System: Research and Forecast, 3rd ed., C. Chang, R. Johnson, and H. Kuo, Eds., World Scientific, 119130.

Li, T., 2014: Recent advance in understanding the dynamics of the Madden-Julian oscillation. J. Meteor. Res., 28, 1-33, https:// doi.org/10.1007/S13351-014-3087-6.

, and B. Wang, 1994: The influence of sea surface temperature on the tropical intraseasonal oscillation: A numerical study. Mon. Wea. Rev., 122, 2349-2362, https://doi.org/10.1175/15200493(1994)122<2349:TIOSST>2.0.CO;2.

, and F. Hu, 2019: A coupled moisture-dynamics mode of the Madden-Julian oscillation: Convection interaction with first and second baroclinic modes and planetary boundary layer. 
Climate Dyn., 53, 5529-5546, https://doi.org/10.1007/s00382019-04879-x.

, L. Wang, M. Peng, B. Wang, C. Zhang, W. Lau, and H.-C. Kuo, 2018: A paper on the tropical intraseasonal oscillation published in 1963 in a Chinese journal. Bull. Amer. Meteor. Soc., 99, 17651779, https://doi.org/10.1175/BAMS-D-17-0216.1.

— , J. Ling, and P. Hsu, 2020: Madden-Julian oscillation: Its discovery, dynamics, and impact on East Asia. J. Meteor. Res., 34, 20-42, https://doi.org/10.1007/s13351-020-9153-3.

Liebmann, B., and C. A. Smith, 1996: Description of a complete (interpolated) outgoing longwave radiation dataset. Bull. Amer. Meteor. Soc., 77, 1275-1277, https://doi.org/10.1175/1520-0477-77.6.1274.

—, H. H. Hendon, and J. D. Glick, 1994: The relationship between tropical cyclones of the western Pacific and Indian Oceans and the Madden-Julian oscillation. J. Meteor. Soc. Japan, 72, 401412, https://doi.org/10.2151/jmsj1965.72.3_401.

Liu, P., and Coauthors, 2009: An MJO simulated by the NICAM at 14- and 7-km resolutions. Mon. Wea. Rev., 137, 3254-3268, https://doi.org/10.1175/2009MWR2965.1.

Madden, R. A., and P. R. Julian, 1972: Description of global-scale circulation cells in the tropics with a 40-50 day period. J. Atmos. Sci., 29, 1109-1123, https://doi.org/10.1175/15200469(1972)029<1109:DOGSCC > 2.0.CO;2.

Maloney, E. D., 2009: The moist static energy budget of a composite tropical intraseasonal oscillation in a climate model. J. Climate, 22, 711-729, https://doi.org/10.1175/2008JCLI2542.1.

_ Á. F. Adames, and H. X. Bui, 2019: Madden-Julian oscillation changes under anthropogenic warming. Nat. Climate Change, 9, 26-33, https://doi.org/10.1038/s41558-018-0331-6.

Raymond, D. J., and Ž. Fuchs, 2009: Moisture modes and the Madden-Julian oscillation. J. Climate, 22, 3031-3046, https:// doi.org/10.1175/2008JCLI2739.1.

Rushley, S. S., D. Kim, and Á. F. Adames, 2019: Changes in the MJO under greenhouse gas-induced warming in CMIP5 models. J. Climate, 32, 803-821, https://doi.org/10.1175/JCLI-D-18-0437.1.

Sobel, A., and E. Maloney, 2013: Moisture modes and the eastward propagation of the MJO. J. Atmos. Sci., 70, 187-192, https:// doi.org/10.1175/JAS-D-12-0189.1.

Sperber, K. R., 2003: Propagation and the vertical structure of the Madden-Julian oscillation. Mon. Wea. Rev., 131, 3018-3037, https:// doi.org/10.1175/1520-0493(2003)131<3018:PATVSO>2.0.CO;2.
Wang, B., 1988: Dynamics of tropical low-frequency waves: An analysis of the moist Kelvin wave. J. Atmos. Sci., 45, 2051-2065, https:// doi.org/10.1175/1520-0469(1988)045<2051:DOTLFW>2.0.CO;2.

_ , and H. Rui, 1990: Dynamics of the coupled moist Kelvin-Rossby wave on an equatorial $\beta$-plane. J. Atmos. Sci., 47, 397-413, https:// doi.org/10.1175/1520-0469(1990)047<0397:DOTCMK > 2.0.CO;2.

_, and T. Li, 1994: Convective interaction with boundary-layer dynamics in the development of a tropical intraseasonal system. J. Atmos. Sci., 51, 1386-1400, https://doi.org/10.1175/ 1520-0469(1994)051<1386:CIWBLD>2.0.CO;2.

Wang, L., and T. Li, 2020: Effect of vertical moist static energy advection on MJO eastward propagation: Sensitivity to analysis domain. Climate Dyn., 54, 2029-2039, https://doi.org/10.1007/ s00382-019-05101-8.

,-- E. Maloney, and B. Wang, 2017: Fundamental causes of propagating and nonpropagating MJOs in MJOTF/GASS models. J. Climate, 30, 3743-3769, https://doi.org/10.1175/ JCLI-D-16-0765.1.

—_, - — , and T. Nasuno, 2018: Impact of Rossby and Kelvin wave components on MJO eastward propagation. J. Climate, 31, 6913-6931, https://doi.org/10.1175/JCLID-17-0749.1.

Wang, S., A. H. Sobel, M. K. Tippett, and F. Vitart, 2019: Prediction and predictability of tropical intraseasonal convection: Seasonal dependence and the Maritime Continent prediction barrier. Climate Dyn., 52, 6015-6031, https://doi.org/ 10.1007/s00382-018-4492-9.

Xiang, B., M. Zhao, X. Jiang, S.-J. Lin, T. Li, X. Fu, and G. Vecchi, 2015: The 3-4-week MJO prediction skill in a GFDL coupled model. J. Climate, 28, 5351-5364, https:// doi.org/10.1175/JCLI-D-15-0102.1.

Xie, Y.-B., S.-J. Chen, I.-L. Zhang, and Y.-L. Hung, 1963: A preliminarily statistic and synoptic study about the basic currents over southeastern Asia and the initiation of typhoon (in Chinese). Acta Meteor. Sin., 33, 206-217.

Zhang, C., 2005: Madden-Julian oscillation. Rev. Geophys., 43, RG2003, https://doi.org/10.1029/2004RG000158.

Zhao, C., T. Li, and T. Zhou, 2013: Precursor signals and processes associated with MJO initiation over the tropical Indian Ocean. J. Climate, 26, 291-307, https://doi.org/10.1175/JCLI-D-1200113.1. 